This is an Author's Accepted Manuscript of an article whose final and definitive form, the Version of Record, has been published in the Journal of Electronic Resources Librarianship, 24: 204-211, 2012 [copyright Taylor \& Francis], available online at: http://www.tandfonline.com/doi/full/10.1080/1941126X.2012.706112

\title{
Getting the Most Out of Pay-Per-View: A Feasibility Study and Discussion of Mediated and Unmediated Options
}

Nathan Hosburgh

\begin{abstract}
The increasing costs of science, technology, and medical journals, combined with decreasing or stagnant budgets, have forced libraries to take a hard look at current journal subscriptions. Even when budgets remain stable or increase, they may not keep pace with the escalating costs of subscriptions from various publishers. In the face of potential journal cancellations, some libraries are turning to pay-per-view (PPV) as an alternative method of providing access to material demanded by patrons. This paper discusses PPV options in general and, in particular, a feasibility study carried out at Florida Institute of Technology, in which the library purchased Wiley tokens and used them in both a mediated and unmediated fashion over the course of a year.
\end{abstract}

KEYWORDS PPV, pay-per-view, transactional access, document delivery, Wiley, Elsevier, Ingentaconnect, Get It Now 
Unstable library budgets have forced academic libraries to reconsider current journal subscriptions, particularly from STM publishers. Increasing costs coupled with stagnant or declining budgets have placed many libraries in a difficult situation in terms of providing access to scholarly literature for constituents. In the face of potential journal cancellations, some libraries are turning to pay-per-view (PPV) as an alternative method of providing access to material demanded by patrons.

There are certainly benefits and drawbacks to providing access using a PPV model, and libraries will have to determine whether such a system makes sense in their particular case. At the Florida Institute of Technology (FIT), various PPV options were examined during 2010 after a significant budget cut was projected for the following fiscal year. This article focuses on a feasibility study, during which the library purchased Wiley tokens and used both mediated and unmediated PPV over the course of the trial period.

\section{REVIEW OF THE RECENT LITERATURE}

Although PPV has been around for some time, it has picked up steam and become more of a hot topic within the last few years. The model has been debated philosophically from the standpoint of collection development and access. Against the Grain devoted an entire issue to PPV in 2010. In this issue, Carr (2010) confronted the traditional ideal of perpetual access and contrasted the satisfaction of immediate patron needs with long-term preservation of information. Potential problems with the PPV model are pointed out, such as "increased administrative burdens" and "decreased fiscal control" (Carr, 2010, p. 14). Availability and costs of PPV are determined by publishers and therefore may be unpredictable from one year to the next. Despite these problems, Carr observes that budget cuts are "forcing the moment to its crisis," and PPV is one avenue, among many, for reducing e-resource cost without reducing access.

Schell, Ginanni, and Heet (2010) engaged in a panel discussion of PPV in various formats and shared experiences from their respective institutions. Potential benefits were highlighted: increased access, decreased cost-per-use, no storage costs, more precise usage statistics, and supplement to interlibrary loan. PPV was attempted with Elsevier, EBSCO, Infotrieve, Ingenta, and Ebook Library with varying degrees of success. Despite the obstacles encountered with these platforms, the presenters believed that the PPV model has potential if "publishers are willing to invest in improving their interfaces, accounting mechanisms, and price points" (Schell et al., 2010, p. 88). Given that many libraries are facing reduced budgets, PPV may offer greater "content provision, cost control, and user satisfaction" (Schell et al., 2010, p. 88).

At Lafayette College, a foray into Elsevier's Article Choice program yielded surprising results. All Elsevier subscriptions were cancelled at the end of 2008, and access was opened to virtually all of Elsevier's titles via Article Choice by loading title information into the library catalog and the A-Z list. After the first year, statistics showed that the number of titles used expanded far beyond those to which the library had previously subscribed. Unexpectedly, previously subscribed titles were not among those with the highest use under the PPV model. This experience showed that, given increased access to unsubscribed content, patron use reveals that librarians' selections may not be as on-target as presumed (Hanson \& Heidenwolf, 2010).

In 2009, current practices were examined among libraries offering unmediated PPV for patrons (Carr\&Collins, 2009). Across the libraries surveyed, common themes emerged. Participants cited two main factors for implementing PPV: reducing costs and expanding 
access. Implementation of PPV consisted of determining what categories of users will be allowed to use the service, the point(s) on a library's web presence from which users will be able to reach the service, and/or the way in which faculty members and their departments would be given unmediated access. Most of the participants reported positive experiences with their implementation of PPV and believed that providing access and managing the system were no more cumbersome from an administrative standpoint than managing subscriptions. Carr's and Collins' paper also offers a literature review of articles discussing PPV prior to 2009.

Although Wiley's Article Select PPV model was reviewed by Golderman and Connelly (2007) and promoted by a Wiley representative during a panel discussion at ALA Annual 2009 (Baxmeyer, 2010), the author was unable to find a study in which an institution has actually used Wiley tokens and reported their findings.

\section{PPV MODELS AND PLATFORMS}

A number of providers currently offer prepaid deposit accounts for the purposes of PPV transactional access. The major players include IngentaConnect, Elsevier, Wiley and, more recently, the Copyright Clearance Center. Information below is accurate at the time of writing, but it is subject to change as publishers adjust pricing, models, and so on.

Ingenta offers controlled purchasing via a payment account, allowing some budgetary control while providing patrons access to articles from unsubscribed content. Access can be opened up by IP range or limited to smaller groups of users. Funding may be segmented by department or broken down to even more specific entities, and it is possible to set limits on the amount of spending within a time period or per item. Monthly reports are available so that usage and spending may be tracked.

IngentaConnect offers a wide range of scholarly content from a collection of 2.5 million articles. The cost of individual articles is above average at $\$ 30$ to $\$ 50$ or more, including applicable fees, although discounts are available for large-volume deposit accounts. Remaining funds from one budget year may also be rolled over into the next year. An implementation fee and annual maintenance fees may be assessed; depending on whether an institution is using a standard payment account or opts for the IngentaConnect Complete service. IngentaConnect Complete costs more to set up and maintain but offers the ability to upload details of licensed content from other providers, thereby avoiding duplications of expenditure. OpenURL linking to a link resolver is also possible with "Complete" (Ingenta, 2012).

Elsevier offers a number of PPV models tailored to the user or to the institutional level. Through standard PPV, individual users accessing Elsevier's ScienceDirect platform are able to purchase Elsevier-owned content at $\$ 31.50$ per transaction. Another option, "Article Choice," is available to small and medium-size corporate, academic, and government libraries; eligibility is based on subscription history. Content from journals, books, and reference works may be pre-purchased, although not all content within ScienceDirect is available using Article Choice. As of December 2011, blocks of 100, 200, and 500 articles were priced at $\$ 29, \$ 26$, and $\$ 23$, respectively, providing a discounted price per article. Institutions that have a preexisting agreement with Elsevier may set up a deposit account for "Pre-paid articles." This represents a third PPV option and enables a fixed price per article or chapter, potentially lower than any price available via Article Choice. Access to unsubscribed content is controlled by the institution, and the PPV fees are charged directly to the institution's pre-paid account. "Article Choice" and "Pre-paid articles" allow institutions 
to track usage and generate reports, while all three models enable the user to access content for 24 hours after purchasing (Elsevier, 2012).

Wiley Enhanced Online License customers can use Article Select Tokens to access almost all content on Wiley Online Library (certain journal content is not accessible under Article Select). The standard price for PPV articles is $\$ 35$. Through purchasing Article Select Tokens, libraries can realize considerable cost savings: 100 packs offer a $5 \%$ discount at $\$ 33.25$ each, while 1,500 packs offer a 65\% discount at $\$ 12.25$ each. As with the other PPV platforms, articles are available to view, download, or print for 24 hours after purchase. The biggest downside to Article Select is that tokens expire 1 year from the point of activation; therefore, unused tokens are lost. Authentication options range from IP Address Only Control, in which any user from within your designated IP range can spend tokens, to SuperUser Control, where a small group of users (often library staff) control token use and mediate incoming requests. Monthly usage reports are available to libraries at no extra charge (Wiley, 2012).

The newest PPV model has been introduced by the Copyright Clearance Center in 2011. Their "Get It Now" service offers publisher-quality PDFs of unsubscribed journal content delivered to end users within an hour of ordering. The service can be configured either mediated within ILLiad as an add-on or via the library's link resolver as an unmediated option. Either method enables seamless ordering and automated content fulfillment. Libraries can choose between a pay-as-you-go system with monthly invoicing or a deposit account option, which enables appropriation of funds across a fiscal year. "Get It Now" currently provides access to 8,800 journals from 24 publishers, and article costs range from $\$ 24$ to $\$ 37$ (Copyright Clearance Center, 2012).

\section{FEASIBILITY STUDY}

Evans Library at FIT has been investigating PPV models for some time. In 2011, the library designated funds toward both Elsevier and Wiley deposit accounts, as it appeared that its budget would become adversely affected by looming campus-wide budget cuts. The intent was to shore up access to important content by using extra funds available toward the end of the 2010 fiscal year and, since Wiley's Article Select tokens were good for only 1 year, this presented an opportunity to engage in a "feasibility study" along a defined timeline while providing access to unsubscribed content. Potential demand was difficult to gauge, so the advantage of steep cost savings was realized by purchasing the largest possible block of tokens. This gave plenty of room to try out the model and, because the funds were prepaid, the library did not have to be concerned with unpredictable usage and spending over the course of time.

\section{RESULTS AND DISCUSSION}

The Wiley model presented the library with an opportunity because there were many unsubscribed, yet potentially valuable, titles not allowed for within the normal annual budget. The 1,500 tokens were officially activated in March of 2011 and used over the course of the next year. A single token is worth one article/book chapter and can be used to purchase content from books, current protocols, and major reference works available from Wiley Online Library.

Wiley offers different levels of authentication and control: IP Address, IP Address/

User Registration, and SuperUser (from least to most restrictive). Mediated use of 
the tokens was desired, at least in the beginning, so SuperUser control was selected. The library intended to have patrons pass openURL data from Wiley Online Library (WOL) into its Serials Solutions link resolver to check for full text elsewhere in the collection and, ultimately, into ILLiad if a request for the material was necessary. Document Delivery staff were designated as SuperUsers and could use the tokens when appropriate in lieu of ILL. A workflow was set up in ILLiad that allowed for staff to supply PDFs of Wiley material with relative ease (Hosburgh, 2012).

The library considered setting up WOL as a database option along with the rest of its electronic databases and indexes, but there was an issue that precluded this: Wiley customer support was unable or unwilling to set up our link resolver on WOL. After repeated inquiries, it was apparent that Wiley was unforthcoming. During this time, it was observed that there were few instances when ILL staff could use the tokens in a mediated fashion, so authentication was shifted to IP Address control. This gave all users accessing WOL from within our institutional IP range on-campus unmediated access to the full text of all content on WOL.

Once the authentication was configured, more prominent branding was added in the form of an institutional logo on the IP-recognized WOL site (Figure 1). The WOL was not included as a database option from the library's portal, and this new access was unadvertised, because the library was interested in what kind of use would develop on its own. Google and other internet search engines were the primary mechanisms for discovery and subsequent downloading of content, although unsubscribed Wiley content could be found by searching beyond the library's collection in Serials Solutions' Summon as well. Once patrons selected a PDF from the WOL, they encountered no intermediate page notifying them that the library was paying for the content. Although the larger campus community was not aware of the

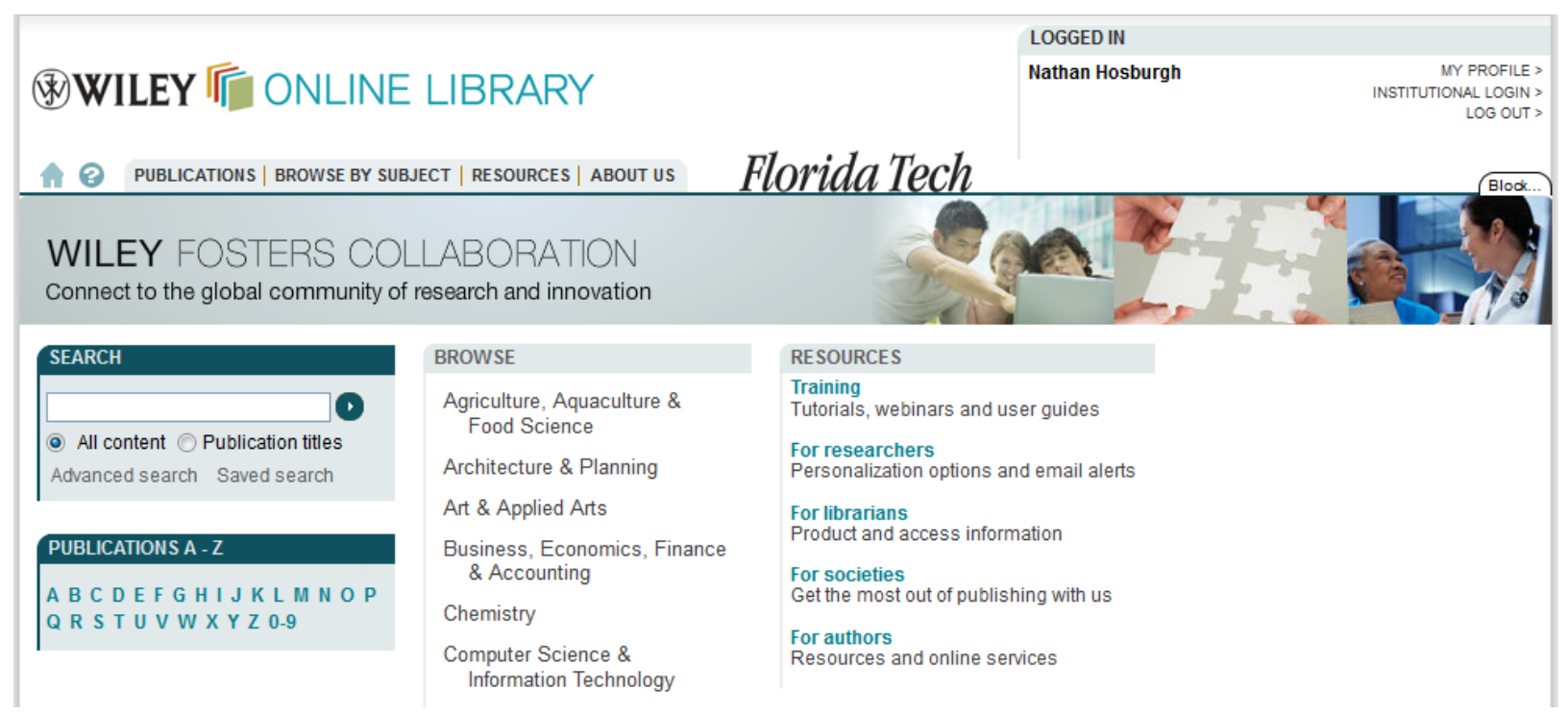

Figure 1 Wiley Online Library with institutional branding.

pilot study, the library branding made it fairly clear that they had landed on FIT's version of the WOL. All library staff were informed of the project since accessing full-text content 
on WOL would trigger PPV token use under IP Address control. The aim was to prevent library staff usage as much as possible.

Unmediated access was turned on in June, 2011, which enabled users to seamlessly connect to content as if the library subscribed to everything within the WOL. Use of the tokens became apparent immediately through viewing active downloads within the Wiley administrative tool (Figure 2). All content downloaded within the past 24 hours is displayed, and subsequent downloads of identical content (within the same 24-hour period) do not result in additional use of tokens. Current token balance is also displayed in real time.

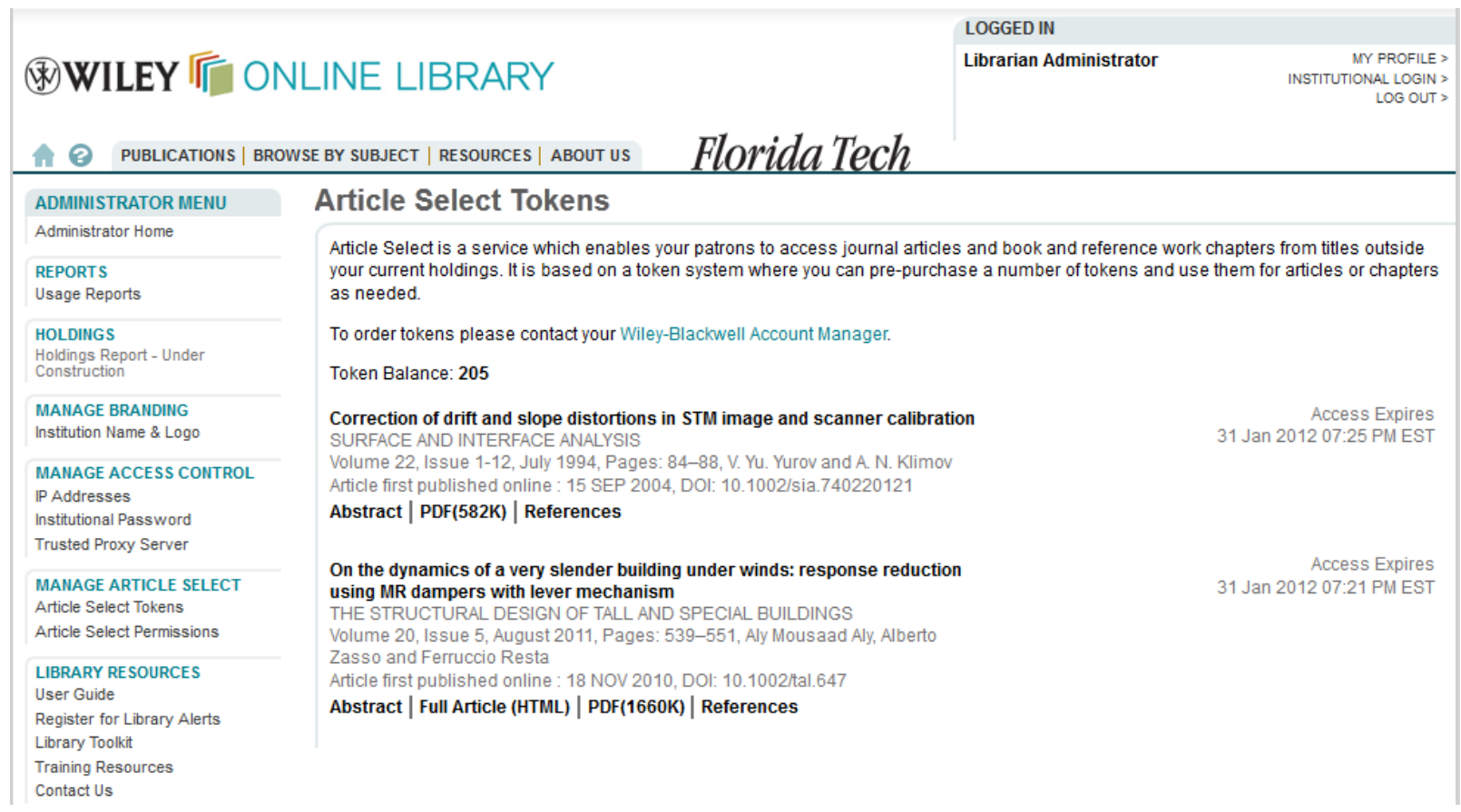

Figure 2 Wiley administrative module.

\begin{tabular}{|c|c|c|c|c|c|c|c|}
\hline 1 & Wiley Article Select Token Usage & \multicolumn{2}{|l|}{ Oct-11 } & & \multirow{2}{*}{$\begin{array}{l}126 \text { out of } 513(25 \%) \text { were available via our library, } \\
\text { predominately in Academic Search Complete. }\end{array}$} & & \\
\hline 2 & Tokens remaining & \multicolumn{2}{|c|}{179} & & & & \\
\hline 3 & Tokens used this month & \multicolumn{2}{|l|}{513} & & & & \\
\hline 4 & Funds used this month & \multicolumn{2}{|l|}{$\$ 6,284.25$} & & & & \\
\hline & Report generated on & \multicolumn{2}{|l|}{$11 / 3 / 2011$} & & & & \\
\hline & Report generated by & \multirow{2}{*}{\multicolumn{2}{|c|}{ N. Hosburgh; S.Odom }} & & & & \\
\hline & & & & & & & \\
\hline 8 & Publication Title & \multirow{2}{*}{$\begin{array}{l}\text { Title ISBN/ ISSN } \\
9780470857502\end{array}$} & Other Access & Content Type & Article / Chapter Title & Month & Date and time \\
\hline 9 & A Climate Modelling Primer, Third Edition " & & $\mathrm{N}$ & BKCHAP & Climate & October & $2011-10-13$ 14:37:52 \\
\hline 10 & Acta Medica Scandinavica & 0001-6101 & $\mathrm{N}$ & JRART & La bilirubine sanguine et urinaire au cours des ictères & October & \multirow{2}{*}{$\begin{array}{l}2011-10-0123: 43: 45 \\
2011-10-0309: 31: 53\end{array}$} \\
\hline 11 & Acta Paediatrica & 0803-5253 & Y & JRART & Coordination of suck-swallow and swallow respiration in preterm infants & October & \\
\hline 12 & Acta Pharmacologica et Toxicologica & $0001-6683$ & $\mathrm{~N}$ & JRART & The Combined Effect of Adrenaline and Sodium Chloride on Blood Pressure in 1 & October & $\begin{array}{l}2011-10-03 \quad 09: 31: 53 \\
2011-10-0516: 34: 49\end{array}$ \\
\hline 13 & Acta Pharmacologica et Toxicologica & $0001-6683$ & $\mathrm{~N}$ & JRART & The Effect of Histamine on Adrenaline Inhibition of the Rat Uterus & October & \\
\hline 14 & Acta Physiologica & $1748-1708$ & Y & JRART & Distinct labelling of fusion events in rat lactotrophs by FM $1-43$ and FM 4-64 is & October & $\begin{array}{lll}2011-11-05 & 16: 1 /: 30 \\
2011-10-25 & 23: 43: 42\end{array}$ \\
\hline 15 & Acta Physiologica Scandinavica & 0001-6772 & $\mathrm{N}$ & JRART & The Use of a Compressed Air Operated Shock Tube for Physiological Blast Res & October & $2011-10-17 \quad 19: 24: 33$ \\
\hline 16 & Acta Physiologica Scandinavica & 0001-6772 & $\mathrm{N}$ & JRART & The Use of a Compressed Air Operated Shock Tube for Physiological Blast Res & October & \multirow{2}{*}{ 2011-10-06 16:07:45 } \\
\hline 17 & Acta Physiologica Scandinavica & 0001-6772 & $\mathrm{N}$ & JRART & The Use of a Compressed Air Operated Shock Tube for Physiological Blast Res & October & \\
\hline 18 & Acta Polymerica & 0323-7648 & $\mathrm{N}$ & JRART & Synthesis of a photosensitive polyimide containing a diazo group and its photoc & October & $\begin{array}{l}2011-10-0413: 18: 43 \\
2011-10-2518: 07-39\end{array}$ \\
\hline 19 & Acta Psychiatrica Scandinavica & $0001-690 \mathrm{X}$ & $\mathrm{N}$ & JRART & The Karolinska Psychodynamic Profile. II. Interdisciplinary and cross-cultural r & October & \multirow{2}{*}{$2011-10-1911: 27: 48$} \\
\hline 20 & Acta Psychiatrica Scandinavica & $0001-690 \mathrm{X}$ & $\mathrm{N}$ & JRART & BORDERLINE SCHIZOPHRENIA IN CHILDREN. & October & \\
\hline 21 & Addiction & 0965-2140 & Y & JRART & Measuring problem video game playing in adolescents & October & $\begin{array}{l}\text { 2011-10-12 08:37:51 } \\
2011-10-31 \text { 10:06:25 }\end{array}$ \\
\hline
\end{tabular}

Figure 3 Modified article select report to determine cross-coverage. 


\section{USAGE REPORTS AND EVALUATION}

Although the Wiley tokens were initially intended to be used mediated via ILLiad, the most interesting findings came from the period of unmediated PPV: June of 2011 to November of 2011. The default Wiley usage reports were of limited usefulness. Reports did contain the publication and article title, but other pertinent pieces of bibliographic data, such as author, volume, issue, and publication date, were missing. Therefore, cross-referencing downloaded Wiley content against the library's holdings turned out to be a tedious process. A portion of a sample report is represented in Figure 3. Extraneous fields were removed from the default reports, and an additional field, "Other Access," was added. Personalized report data were added to the top of the spreadsheet, and these uppermost cells were frozen so that scrolling and sorting of the publication data could be done independently.

To determine cross-coverage, the publication title was first checked against the $A-Z$ list. If it was not found, an " $N$ " was recorded for No in the "Other Access" column. If the publication title was in the A-Z list, a secondary web search was conducted to obtain a complete citation of the article in question. With volume/issue/publication date in hand, access either in another database or in the print periodicals collection could be verified. The WOL also provides access to articles from current protocols and chapters from major reference works. In the case of book chapters, the book title was searched in the online public access catalog, and it was found in some cases that, although the library did not have access to the e-book, the print counterpart was owned. In such cases, the library was paying for electronic content that was owned in print form.

Through analyzing the usage reports, it became apparent that most "other access" was found in EBSCO's Academic Search Complete. Even considering the large amount of titles with embargoed content, much duplicate content was located within this database.

Duplicate content was downloaded by patrons within the year or even within a single month. A single token secures IP access to an individual article for 24 hours. There were instances when a single article was downloaded multiple times, days apart. This may have been due to multiple users accessing identical content, or a single user may have gone back and looked at the same PDF repeatedly, although not within a 24-hour window. This brings attention to the fact that, with the PPV model, the library will certainly be paying for duplicate content-not only content duplicated in other databases but content downloaded multiple times by users on a PPV platform across time.

During the course of unmediated PPV, the duplication of content each month (reflected in the "other access" column) ranged from $25 \%$ to $39 \%$, with an average of $30 \%$. The percent of duplication basically reflects content found elsewhere within the library's collection. In the course of analyzing the reports, it was also found that, although some content was not located within the library's collection, it was located in full text on the web. This access included institutional repositories, PubMed, author's personal websites, arxiv.org, and so on. Because it is often difficult to determine how closely an open-access version of a document parallels the official version published in a journal, the author decided to leave such results out of the final analysis. Regardless, this open-access content does deserve mention as it suggests other access points besides publisher-sponsored content that may satisfy user needs, particularly if there are fewer barriers to access and the content is deemed reliable. 


\section{CONCLUDING OBSERVATIONS AND THOUGHTS}

Each PDF downloaded via the WOL deducted one token and could be construed as a "use," but administrators do not really know how the patron actually made use of such content or whether they made use of it at all. Of course, the same holds true for subscriptions: Aggregate use for a title may be tracked via publisher's data and/or reports from our link resolver, but this gives an incomplete picture at best.

One of the main arguments leveled at PPV is that this form of transactional access does little for collection building. This is true of all PPV content, Wiley included: A library using tokens may not add such content to their permanent collection.

Duplicated content will most certainly be purchased and, once the tokens or funds are exhausted, the question remains: "What has been gained?" Philosophical questions aside, PPV does offer considerable value in that it serves as an affordable alternative to costly subscriptions with low use and traditional interlibrary loan, which is somewhat unreliable in terms of speed and quality and incurs costs of its own, such as borrowing and copyright fees. The usage data may also be employed to determine whether certain titles should be looked at more closely for possible subscription in the future. Conversely, either a library without existing Wiley subscriptions or a library looking to drop all or part of its titles might be able to purchase Wiley tokens in lieu of subscriptions altogether.

The most prominent finding during the study was the amount of duplication found during the unmediated portion of the project. This brings into question the cost-effectiveness of such PPV. If $30 \%$ or more content acquired via PPV is duplicated elsewhere in the library's collection, this may not be the best use of funds. Conversely, certain libraries may be more concerned with convenience and sweeping away barriers to access than making sure they are not paying twice. Mediated PPV via a system such as ILLiad certainly mitigates the potential for purchasing content licensed or owned by the library and adds confidence that a genuine need has been expressed for such content.

The PPV model via the WOL offers libraries the flexibility to design a system that is mediated, unmediated, or a blend of both. FIT was eventually able to place its OpenURL link resolver on results from the WOL, enabling requests brought into ILLiad to be fulfilled quickly and easily. Due to the authentication control methods available via Wiley, it is not quite possible to set up specific subsets of the campus with unmediated PPV, such as departments or groups of faculty. Despite its limitations, the Wiley token system does offer considerable efficiencies, especially as larger blocks of tokens are purchased, price per article decreases, and a library realizes greater economies of scale.

The "Get It Now" service recently made available from the Copyright Clearance Center offers pay-as-you-go PPV of content from a growing set of publishers, including Wiley, Elsevier, Springer, and more. This alleviates one of the major problems found with the Wiley model: The uncertainty regarding the amount of tokens to purchase, as usage is difficult to predict and the tokens expire after 1 year. Transactional access accounts that offer more flexibility may be a better option for smaller academic institutions with tighter budgets. Regardless of the platform, these types of PPV systems will certainly remain in place and likely see more buy-in from libraries that are challenged to provide access to the wealth of discoverable resources in our information-rich world. 


\section{REFERENCES}

Baxmeyer, J. (2010). Pay-per-view options: Is transactional access right for my institution? A report of the ALCTS cataloging and classification section electronic resources interest group program. American Library Association Annual Conference, Chicago, July 2009. Technical Services Quarterly, 27(3), 304-308.

Carr, P., \& Collins, M. (2009). Acquiring articles through unmediated, user-initiated pay-per-view transactions: An assessment of current practices. Serials Review, 35(4), 272-277.

Carr, P. (2010). Forcing the moment to its crisis: Thoughts on pay-per-view and the perpetual access ideal. Against the Grain, 21(6), 14, 16.

Copyright Clearance Center. (2012). Get it now. Retrieved from http://www.copyright.com/content/ cc3/en/toolbar/productsAndSolutions/getitnow.html

Elsevier. (2012). SciVerse: Pre-paid articles. Retrieved from http://www.info.sciverse.com/ sciencedirect/buying/individual article purchase options/Pre paid articles

Golderman, G., \& Connolly, B. (2007). Pay by the slice. Library Journal, 18-20(22), 24-26.

Hanson, M., \& Heidenwolf, T. (2010).Making the right choices: Pay-per-view use data and selection decisions. College \& Research Libraries News, 71(11), 586-588.

Hosburgh, N. (2012, March). Transactional access within and without ILLiad: An examination of mediated and unmediated pay-per-view options. ILLiad International Conference, Virginia Beach, VA.

Ingenta. (2012). IngentaConnect: Document delivery. Retrieved from http://www.ingentaconnect. com/about/librarians/purchasing articles

John Wiley \& Sons. (2012). Wiley: Article select. Retrieved from http://olabout.wiley.com/ WileyCDA/Section/id-406741.html

Schell, L., Ginanni, K., \& Heet, B. (2010). Playing the field: Pay-per-view E-journals and E-books. The Serials Librarian, 58(1-4), 87-96. 